\title{
GROWTH ESTIMATION BY AREAL MEASURING OF CELL COLONIES IN ROLLER-TUBE CULTURES*
}

\author{
KOUICHI TAKANO AND MASA-ATSU YAMADA \\ Department of Pathology, National Institute of Health, Tokyo
}

(Received: December 14th, 1955)

Growth of cells cultivated in vitro can be estimated by various methods devised by many research workers in the field of tissue culture studies. Generally speaking, those estimating methods may be divided into some lines, that is, areal measuring of cell colonies in cultures with solid phase of growth, cell number counting in the state of cell suspension, and many other physicochemical methods.

Areal measuring method originally adopted by Carrel(1) on coverslip or flask cultures supported by plasma clot, was later modified by many workers from several directions, following the improvement of tissue culture technique itself. While coverslip or flask culture technique had been thus improved, Gey(2) devised another method of tissue culture, so-called roller-tube technique, on the basis of Carrel's suggestion(3), and he and his associates(4) ${ }^{(4)}$ succeeded to separate and establish a cell strain of rat origin under continuous in vitro cultures using this roller-tube technique. This strain, which has undergone the later change in biological character to become malignant, grows easily on the glass wall of the tube without any substrate, forming almost monolayer cell colonies. Ehrmann and Gey ${ }^{(5)}$ used this characteristic strain to evaluate nutritional substances in vitro, and obtained more precise results than those in the past.

Meanwhile, Earle and co-workers(6) established, after many years' studies on tissue culture, a more accurate quantitative method of growth estimation by cell nuckei counting, depending on their own device of replicate suspension cultures ${ }^{(7)}$. This counting method can represent the growth of cells more exactly than areal measuring method, though it is more or less complicated in handling or procedure.

The present authors have been studying on tissue culture from several viewpoints. Our special interest is in cultivating malignant tumor cells to pursue their biological characters in rather broad meaning.

In the present paper, will be reported the results of several experiments concerning fundamental culture conditions of normal tissue cells including embryonic heart of chick, mouse, and human origins. Roller-tube technique and areal growth measuring of cell colonies were used throughout experiments. Some methodological points will be discussed.

* The content was partly reported at the 13th General Meeting of the Japanese Cancer Association, in April, 1954, at Nagoya, and was abstracted in Gann, 45, 453-455, 1954. 


\section{MATERIALS AND METHODS}

Kinds of tissues cultivated: From 1st to 5th culture generations of embryonic heart of chick, mouse, and human origins were used.

Culture method: Roller-tube technique was used almost following Gey's original method ${ }^{5}$ with slight modifications in detail. Tissues to be cultivated were cut with a pair of fine knives into small fragments of about $1 \times 1 \times 1 \mathrm{~mm}$ size. As supporter of tissues to be cut, we prepared a hollow-slide glass with films lightly patched on both sides near the hollow, and the slide glass was covered with a Petri dish while it was not used. A bent-tip pipette was used for implanting the fragments on the tube walls. As to substrate, and number and position of fragments, description will be made afterwards.

Culture tube was $15 \times 170 \mathrm{~mm}$ in size, with ordinary shape, stoppered with rubber double-cap, slanted at an angle of 5 degrees, and rotated at about 15 r.p.h. Culture medium was composed of $50 \%$ chick embryo extract, human placental cord serum*, and Hanks' balanced salt solution, at the ratio of $2: 4: 4$, delivered in $0.6 \mathrm{cc}$ to each tube, and renewed twice a week.

Then some changes were given to culture conditions in such mechanical aspects as size, number, and position of explants, rotation, substrate, temperature, and $\mathrm{pH}$, and then their respective effects on cell growth were investigated according to an estimating standard. Other conditions including the nutritional requirement of cells will be discussed in other papers.

Estimation of outgrowth: As the technique for measuring each colony, a procedure was performed first, in which the outline of each colony was sketched on a paper by means of a describing ocular equipment, and then area of the figure was measured with a planimeter. The procedure was later altered, namely, each colony was measured directly with a fine lattice set in the ocular lens, and the value of

\section{$\checkmark$ maximum diameter $\times$ minimum diameter}

was supposed to represent its size.

The regularized procedures as mentioned later could make the measurement rather precise, nevertheless there still remained a weak point in areal measurement itself that increase of area could not always represent exact multiplication of cells. So, while measurement was continued up to the 7 th to 12 th days of cultivation, cytological observations and results of passage to following generations were considered as well.

\section{RESULTS}

Size, number and position of tissue fragments affecting the relative growth ratio in areal increase: By many investigators, the ratio of area of outgrowth at a point of culture stage to that of the original explant had been used as a

* The authors wish to thank Dr. T. Kinoshita, the Saiseikai Hospital, for his courtesy in collecting placental cord blood. 
scale for growth estimation. In several series of our early experiments, as seen in Figs. 1 and 2, the variation in the relative growth ratio (RGR) seemed to be inversely proportional to the size of original explant (coefficient of correlation $=-0.46, t_{0}=3.232$, degree of freedom $\left.=39, P<0.01\right)$.

Fig. 1

Comparative effect between number and size of original explant on the relative growth ratio (Mouse embryonic heart, on the 4th day of cultivation)

- one of 3 colonies in a tube

- one of 6 colonies in a tube

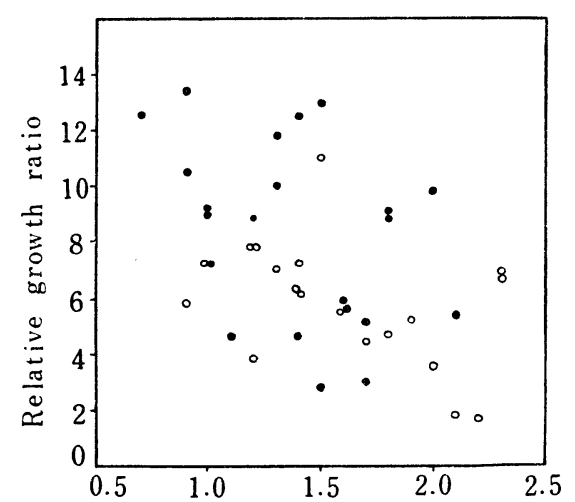

\begin{tabular}{l|r|r|c}
\multicolumn{4}{c}{ Area of original explant $\left(\mathrm{mm}^{2}\right)$} \\
\hline Factor & Variance & DF* & $F_{0}$ \\
\hline Number & 3735.72 & 1 & $4.97(P<0.05)$ \\
Size & 1712.74 & 3 & $2.28(P<0.10)$ \\
$\mathrm{N} \times \mathrm{S}$ & 518.43 & 3 & $0.69(P>0.20)$ \\
$\mathrm{R} * *$ & 752.02 & 33 & \\
$*$ Degree of freedom & $* *$ Remainder
\end{tabular}

Fig. 2

Comparative effect between position and size of original explant on the relative growth ratio (Same data as fig. 1)

. $1.5 \mathrm{~cm}$ from bottom

$\triangle 2.5 \mathrm{~cm}$

$\times 3.5 \mathrm{~cm}$



Area of original explant $\left(\mathrm{mm}^{2}\right)$

\begin{tabular}{l|r|r|c}
\hline Factor & Variance & DF* & $F_{0}$ \\
\hline Position & 3549.80 & 2 & $5.03(P<0.05)$ \\
Size & 1112.65 & 1 & $1.58(P>0.20)$ \\
$\mathrm{P} \times \mathrm{S}$ & 934.77 & 2 & $1.04(P>0.20)$ \\
$\mathrm{R} * *$ & 705.50 & 35 & \\
$*$ Degree of freedom & $* *$ Remainder
\end{tabular}

But further investigations proved the fact that the influence of number and position of fragments in a tube was significantly larger than that of original size. Fig. 1 shows distribution of RGR values against original size of each colony belonging to two groups, one containing 3 colonies in a tube and the other 6 . In Fig. 2, the same data as above was differentiated following the position in a tube, namely, $1.5,2.5$, and $3.5 \mathrm{~cm}$ from the bottom. Statistical analysis was done as shown in the under part of each figure.

On the basis of the results, a standardization was done in later estimations; six explants were implanted in each tube, three sticked to inner surface of the wall on one side and the others on the opposite side, and their positions were fixed to be $1.5,2.5$, and $3.5 \mathrm{~cm}$, respectively, from the bottom on both sides. Five tubes thus prepared made one experimental group. 
Effect of rotation on areal growth: Rotation rate was fixed to be 15 r.p.h. in one group and compared with the other group left stationary. Fig. 3 shows the result that the areal growth of mouse embryonic heart in rotated group was superior, though not so decisively, to that in stationary group $(P<0.10)$.

Fig. 3

Effect of rotation on the areal growth of mouse embryonic heart



Fig. 4

Effect of substrate on the areal growth of chick embryonic heart

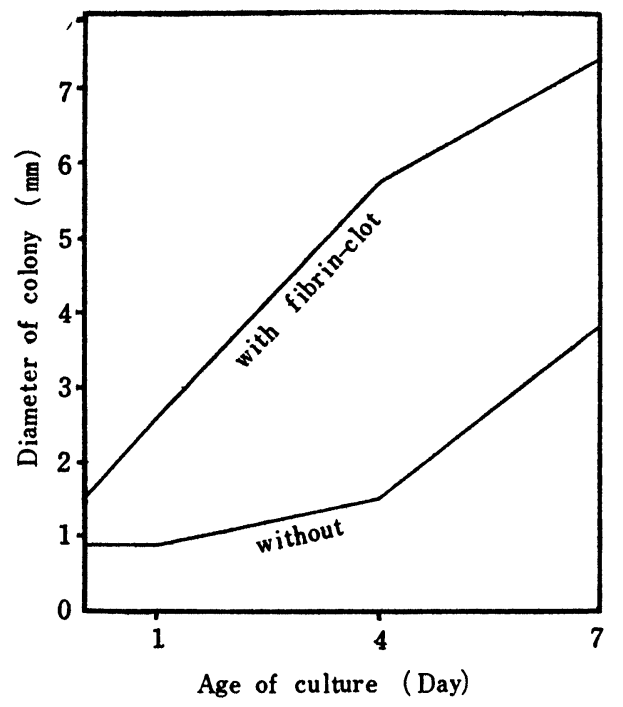

In the case of standstill, culture fluid became somewhat turbid in a few days, especially with some fine deposits appearing linearly along the lying side of a tube, that might come from embryo extract, which could not been completely cleared up by renewal of fluid. In the experiments reported in this paper, the compositive ratio of extract in the medium was rather high, 2 parts of 10, and the fact was found, in another series of experiments using a medium composed 
of less extract and square shaped tubes, that such inconvenience could be avoided.

Effect of substrate: Fibrin-clot was made by a combination of 2 drops of heparinized chicken plasma and 3 drops of $50 \%$ chick embryo extract to support tissue fragments on the wall of tubes. In some cases, cultures growing on the

Fig. 5

Comparative effect between $37^{\circ} \mathrm{C}$ and $38^{\circ} \mathrm{C}$ on the areal growth of chick and human embryonic heart

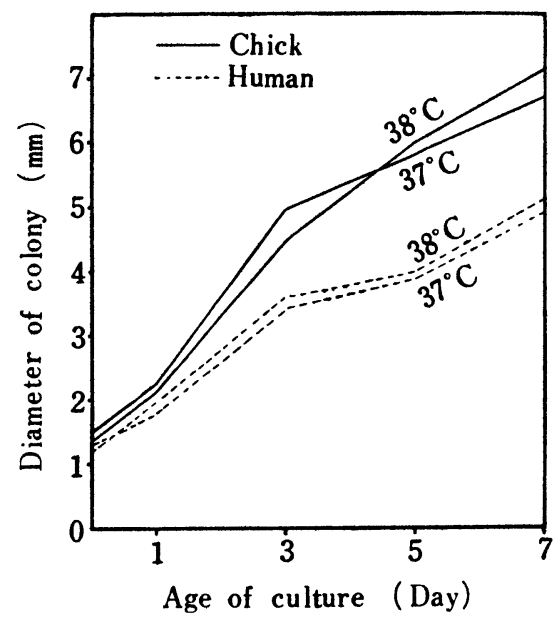

Fig. 6

Comparative effect between $37^{\circ} \mathrm{C}$ and $32^{\circ} \mathrm{C}$ on the areal growth of chick and mouse embryonic heart

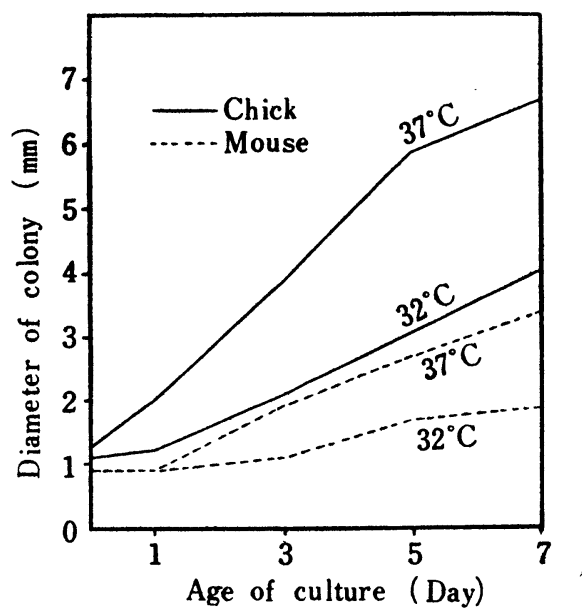

supporting fibrin-clot and directly on the glass wall were compared with each other. In the cultures with fibrin-clot, heart fibroblasts from embryos of chick, mouse, and human origins grew better than in the case without substrate (Fig. 4). Transfer to the next generation in the former was successful up to the 30th day or a little later, with the best result gained on the 7 th to 14 th days. In mouse tissues, subcultures could hardly be completed without fibrin-clot.

Effect of temperature: It is generally accepted that the most effective temperature for chick tissues is $38^{\circ} \mathrm{C}$, while mammalian tissues prefer $37^{\circ} \mathrm{C}$ or a little lower. Three sorts of embryonic tissues were examined how they would grow under three grades of temperature, $38^{\circ}, 37^{\circ}$, and $32^{\circ} \mathrm{C}$. There was not any difference in growth rate in every case between $37^{\circ}$ and $38^{\circ} \mathrm{C}$ as Fig. 5 shows, while the rate was smaller at $32^{\circ}$ than at $37^{\circ} \mathrm{C}$ as illustrated in Fig. 6 with the statistical significance $(P<0.01)$.

Cytological observations showed some changes, as fat depositing determined by osmium staining (cf. Plate 3), pigmentation, or vacuolization appeared to a little higher extent in the case of $38^{\circ}$ than $37^{\circ} \mathrm{C}$. At $32^{\circ} \mathrm{C}$ cell growth was very constant for a certain period of time, though growth rate itself was rather small, and cells seemed to be in good condition by microscopical examination. It may be said a rather low temperature is more available for long-term cultures. 
Effect of $p H$ : As the optimal $\mathrm{pH}$ for growth had been noticed depending on species of donors of tissues, three grades of $\mathrm{pH}, 6.8,7.4$, and 8.0, were compared with one anohter about their effect on growth of chick and mouse heart tissues. Not so much difference was obtained through both species; to speak generally,

Fig. 7

Effect of various $\mathrm{pH}$ on the areal growth of chick embryonic heart

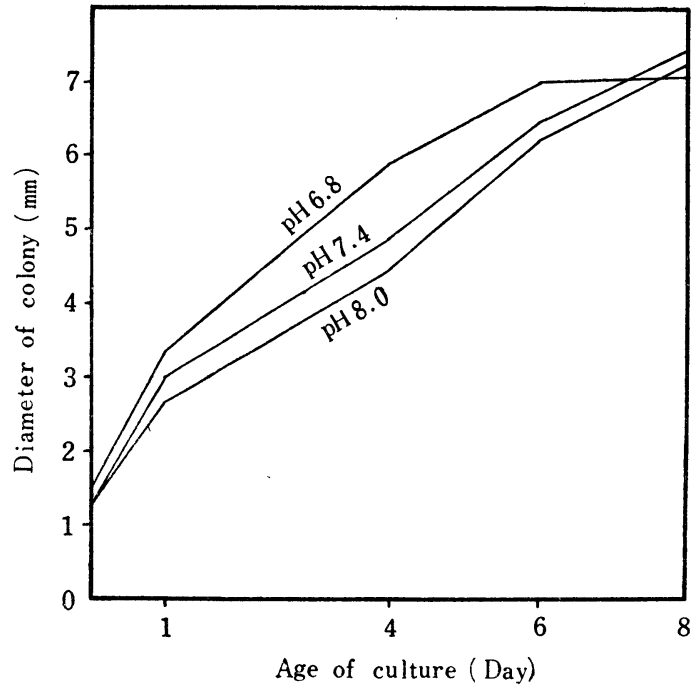

the lower was $\mathrm{pH}$ within the above mentioned range, the greater was the intial growth of cells, though the group of $\mathrm{pH} 6.8$ showed retardation since the 6 th day of cultivation (Fig. 7). Then as a routine work, the authors have been using the initial $\mathrm{pH} 7.2$ to 7.4, renewing medium twice a week, and adjusting $\mathrm{pH}$ by using proper dose of $1.4 \% \mathrm{NaHCO}_{3}$ whenever it becomes lower than 7.0.

\section{Discussion}

Estimation of cell growth will make the basis of information about biological characteristics of cells growing in vitro, and many works in the research field of tissue culture has been basing the reliability on their methodological preciseness.

Outgrowth measurement of cell colonies, used by us at present, has been devised to be accurate as possible by means of standardization in implanting cell colonies, so that it may represent cell growth at least for a certain period of time, even if somewhat relatively in comparison with the direct cell counting method, the latter being discussed in other reports.

The results obtained concerning culture conditions of normal embryonic heart tissue cells, may not represent at once those of other sorts of cells, especially neoplasms. They will, however, be able to offer some biologically fundamental knowledge of growth characteristics of tissue cells and convenience for comparison between normal and malignant cells under in vitro conditions. 


\section{SUMMARY}

In estimation of cell growth in roller-tube cultures by measuring areal growth of cell colonies, it was discovered that the number and position of each explant in a tube had significant influence on the relative growth ratio of its outgrowth, and then a standardization about them in implantation was taken into consideration.

Area of each cell colony was measured successively by using a fine lattice inserted in the ocular lens, expressed in mean diameters, and then that value of each group was compared statistically with each other.

Using above mentioned procedures, several fundamental culture conditions including rotation, substrate, temperature, and $\mathrm{pH}$ were examined to find out the most suitable conditions for growth of embryonic heart tissue of chick, mouse, and human origins. There was seen no characteristic behavior peculiar to any of these three sorts of tissues so far as these culture conditions were concerned. Dealt with uniformly as rotated, sticked on fibrin-clot, and incubated at $37^{\circ} \mathrm{C}$ with initial $\mathrm{pH}$ 7.4, they have become possible to be cultivated continuously through several passages, except mouse tissue with some difficulties.

Results with normal tissue cells may be regarded as a basis on which further investigations will be made about neoplastic cells.

\section{REFERENCES}

1) Carrel, A.: Present condition of a strain of connective tissue twenty-eight months old. J. Exper. Med., 20, 1, 1914.

2) Gey, G. O.: An improved technic for massive tissue culture. Am. J. Cancer, 17, 752-756, 1933.

3) Carrel, A.: Neue Untersuchungen über das selbständige Leben der Gewebe und Organe. Berl. klin. Wchschr., 1, 1097-1101, 1913.

4) Gey, G. O., Hanks, J. H. \& Barrett, R.: Retardation of growth and metabolism of normal and malignant cells during continuous cultivation. Growth, 12, 69-105, 1948.

5) Ehrmann, R. L. \& Gey, G. O.: The use of cell colonies on glass for evaluating nutrition and growth in roller-tube cultures. J. Nat. Cancer Inst., 13, 1099-1118, 1953.

6) Sanford, K. K., Earle, W. R., Evans, V. J., Waltz, H. K. \& Shannon, J. E.: The measurement of proliferation in tissue cultures by enumeration of cell nuclei. $\mathrm{J}$. Nat. Cancer Inst., 11, 773-795, 1951.

7) Evans, V. J., Earle, W. R., Sanford, K. K., Shannon, J. E. \& Waltz, H. K.: The preparation and handling of replicate tissue cultures for quantitative studies. J. Nat. Cancer Inst., 11, 907-927, 1951. 


\section{Plate 1.}

Chick embryonic heart. 6th culture generation. Giemsa staining. $\times 400$.

Plate 2.

Chick embryonic heart. 6th culture generation. Giemsa staining. $\times 800$. Shows a mitotic figure.

\section{Plate 3.}

Chick embryonic heart. 3rd culture generation. Osmium staining. $\times 200$.

\section{Plate 4.}

Mouse embryonic heart. 3rd culture generation. Giemsa staining. $\times 800$.

\section{Plate 5.}

Human embryonic heart. 2nd culture generation. Unstained. $\times 60$. Shows whole view of outgrowth.

\section{Plate 6.}

Human embryonic heart. 2nd culture generation. Giemsa staining. $\times 800$. 


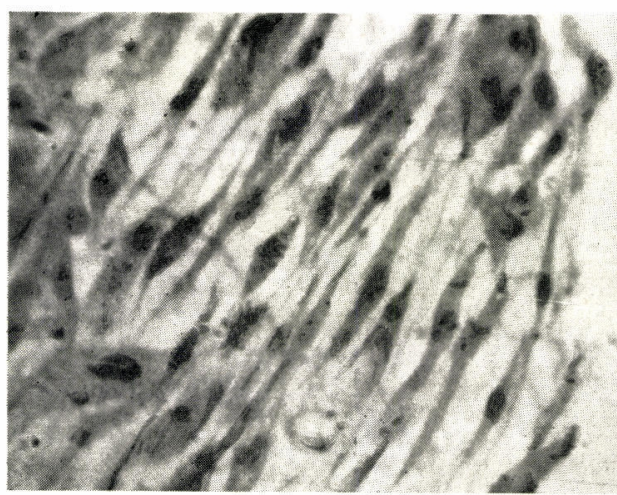

Plate 1

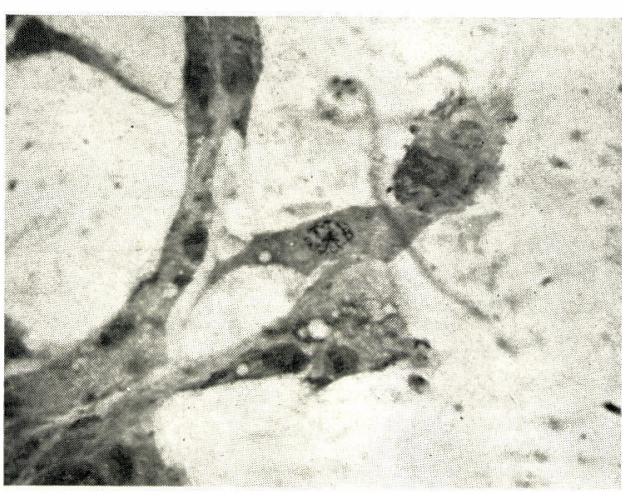

Plate 2

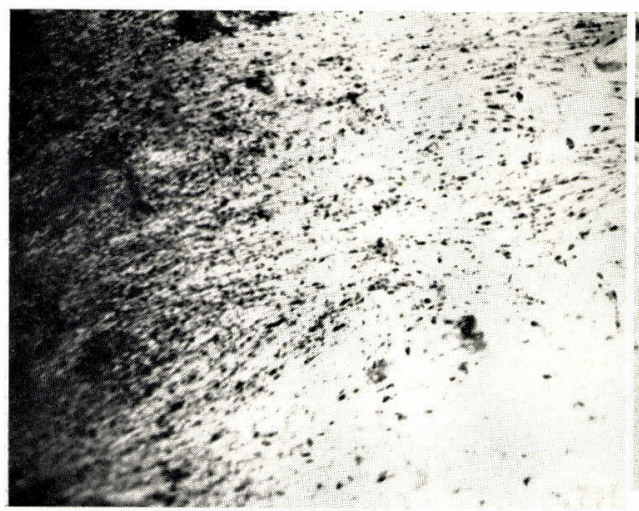

Plate 3



Plate 5

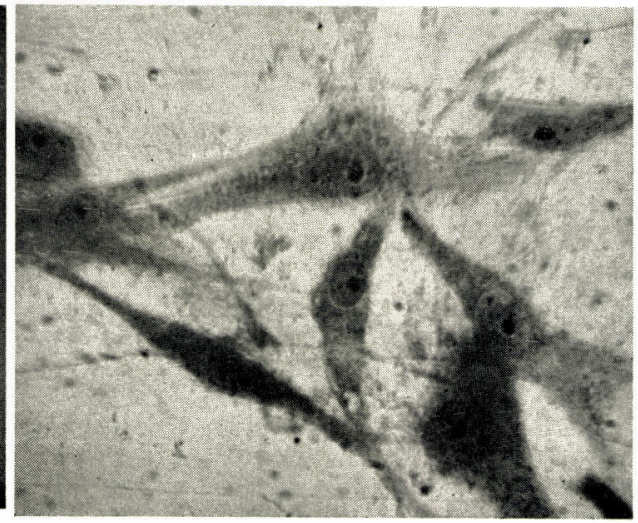

Plate 6 